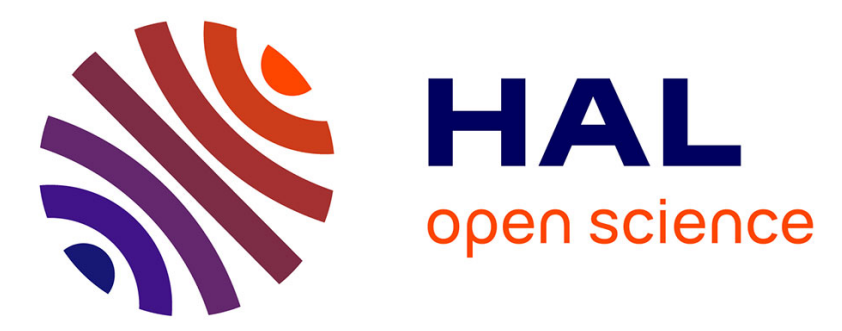

\title{
Self-Assembly Polymorphism of Regioisomeric Diketopyrrolopyrrole-Based $\pi$-Conjugated Organic Semiconductors
}

Jinxing Li, Xinrui Miao, Lei Ying, Fabien Silly, Chunshan Che, Gang Kong, Wenli Deng

\section{To cite this version:}

Jinxing Li, Xinrui Miao, Lei Ying, Fabien Silly, Chunshan Che, et al.. Self-Assembly Polymorphism of Regioisomeric Diketopyrrolopyrrole-Based $\pi$-Conjugated Organic Semiconductors. Journal of Physical Chemistry C, 2019, 123 (2), pp.1185-1193. 10.1021/acs.jpcc.8b08701 . hal-02433442

\section{HAL Id: hal-02433442 https://hal.science/hal-02433442}

Submitted on 9 Jan 2020

HAL is a multi-disciplinary open access archive for the deposit and dissemination of scientific research documents, whether they are published or not. The documents may come from teaching and research institutions in France or abroad, or from public or private research centers.
L'archive ouverte pluridisciplinaire HAL, est destinée au dépôt et à la diffusion de documents scientifiques de niveau recherche, publiés ou non, émanant des établissements d'enseignement et de recherche français ou étrangers, des laboratoires publics ou privés. 


\title{
Self-Assembly Polymorphism of Regioisomeric Diketopyrrolopyrrole Based $\pi$-Conjugated organic Semiconductors
}

\author{
Jinxing Li,${ }^{\dagger}$ Xinrui Miao, ${ }^{*}{ }^{\dagger,}{ }^{\S}$ Lei Ying,${ }^{\dagger}$ Fabien Silly, ${ }^{*},{ }^{\S}$ Chunshan Che,${ }^{\dagger}$ Gang Kong, ${ }^{\dagger}$ Wenli Deng ${ }^{\dagger}$
}

${ }^{\dagger}$ College of Materials Science and Engineering, South China University of Technology, Guangzhou 510640, People's Republic of China.

Institute of Polymer Optoelectronic Materials and Devices, State Key Laboratory of Luminescent Materials and Devices, South China University of Technology, Guangzhou 510640, People's Republic of China. §TITANS, SPEC, CEA, CNRS, Université Paris-Saclay, CEA Saclay, Gif sur Yvette, F-91191, France

Corresponding authors: Xinrui Miao (msxrmiao@scut.edu.cn)

Fabien Silly (fabien.silly@cea.fr)

\begin{abstract}
The 2D molecular assemblies of two structural isomers $p$-DBPy and $d$-DBPy relevant to the field of organic electronics. These two molecules only differ in the position of pyridyl N-atoms,. The solution concentration and solvent effects on the adlayer morphology are investigated using scanning tunneling microscopy (STM). Both kinds of molecules could exhibit obviously different molecular conformations and packing patterns, which demonstrate that the variation of the $\mathrm{N}$-atom position in the pyridyl leads to different intermolecular interactions and stacking styles. Positioning the pyridyl $\mathrm{N}$-atoms proximal to the central conjugated core could change the molecular conformation into a banana shape by bending the molecule, however, the $d$-DBPy molecule in which pyridyl $\mathrm{N}$-atoms are distal to the central conjugated cores keep a linear shape in the monolayer. This work illustrates that altering the position of N-atoms in pyridyl could influence the film morphology and provides a deeper insight from molecular scale to understand the molecular conformation in different packing patterns, which are benefit for the rational design of future advanced optoelectronic devices.
\end{abstract}




\section{Discussion}

STM shows that $p$-DBPy and $d$-DBPy molecules self-assemble into different patterns under different solution concentrations at the 1-phenyloctane/HOPG interface.... At low concentration the the powder color is purple black for $p$-DBPy, whereas it is orange ford-DBPy molecules. At high concentration the powder color is purple red for the two molecules. The color change indicates that molecular aggregation or packing has been modified(REFERENCE). STM data previously showed that $p$-DBPy molecules can adopt different conformations. The color change can also reflect the variation of molecular conformation. The conformation for the conjugated core of $p-\mathrm{DBPy}$ is linear in solution, however, the conformation is curve in solid states (solid powder and film). However, for $d$-DBPy, the colors for the solution and solid state has not obviously significant change, indicating the molecules keep the same linear molecular conformation.
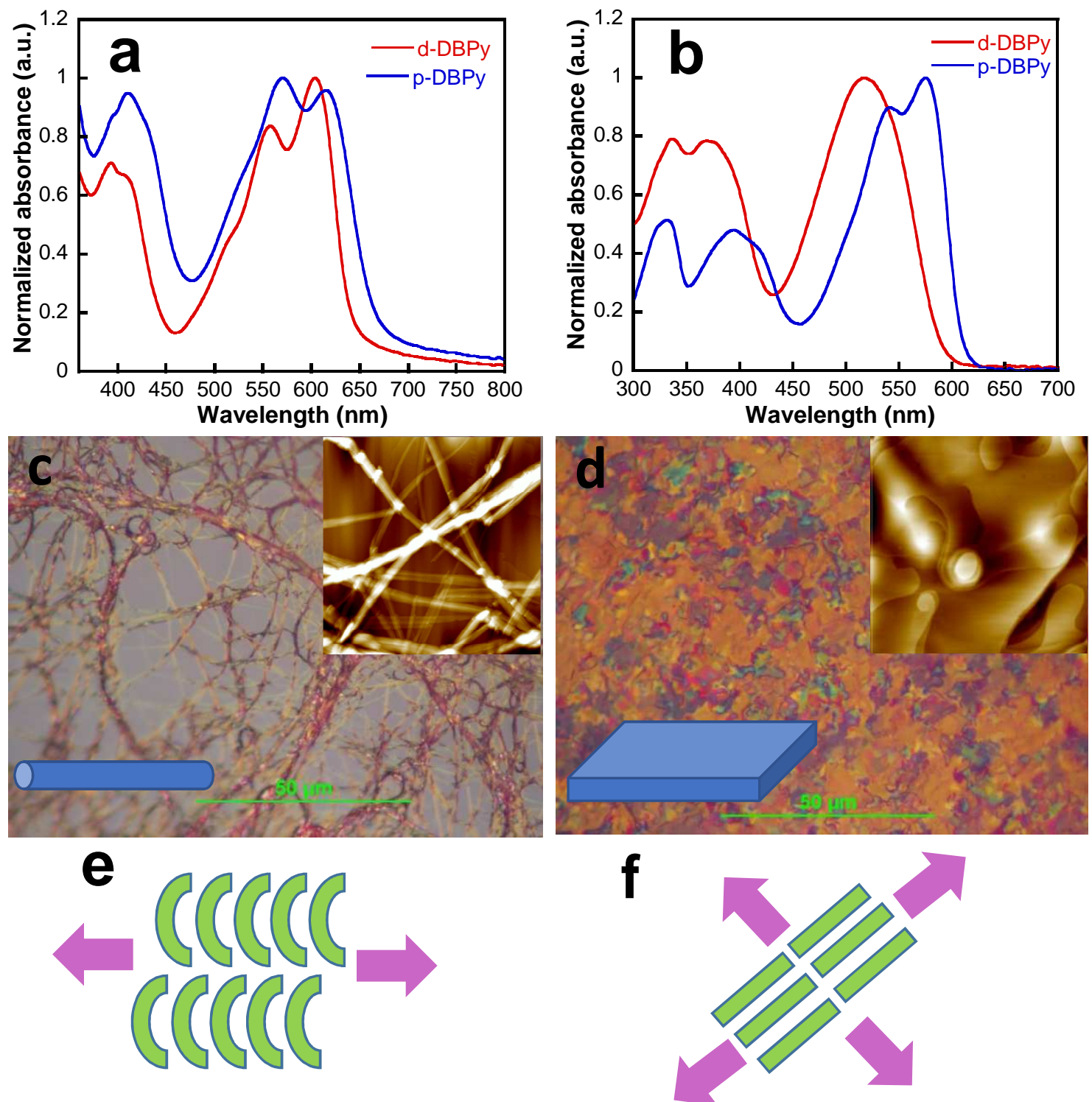

H-aggregation 
Figure 6. (a,b) UV-vis absorption spectra of $p-D B P y$ and $d$-DBPy molecules as thin films (a) and in toluene (b). (c,d) Polarized optical microscopy (POM) images showing the aggregations of $p-\mathrm{DBPy}(\mathrm{c})$ and $d-\mathrm{DBPy}$ (d) on mica surfaces. Insets are the AFM images showing the morphology of the films. The samples were prepared with an air-drying method. (e,f) Proposed models showing the aggregation modes.

Figure 6a shows the UV-vis spectra of the molecular thin films, whereas the UV-vis spectra of the molecules in solutions is presented in Fig.6b. The spectra reveal that the adsorption peaks of $p-\mathrm{DBPy}$ and $d$-DBPy films are blue-shifted in comparison with the peaks measured in solutions (Figure 6b). Ref.[47,48] propose that this shift results from different H-aggregation. Molecular aggregation is investigated using Polarized optical microscopy (POM) and atomic force microscopy (AFM), (Figure 6c,d). AFM and POM images reveals that the $p$-DBPy molecules form linear fibers (Fig.6c), whereas $d-$ DBPy molecules form multilayer flat films. $p-D B P y$ form the linear aggregation in the films owing to the intraand intermolecular interactions, so the H-aggregation is formed when the molecules stack by a parallel arrangement with the banana-like conformation (Figure 6e). $d-D B P y$ with the linear conformation form the lamellar structure with the H-aggregation (Figure 6f). According to the models, the film of p-DBPy molecules grows fast along two directions as the pick arrows indicated, while the $p$-DBPy film extends towards four directions. Because the films are prepared with relative high solution concentration, the self-organization of molecules in the films are the same with 2D molecular self-assembly obtained at high solution concentration. Thus, the STM results could interpret the nature of molecular packing and morphologies of the films from the molecular scale. It can be concluded that the 2D assembly of $p-\mathrm{DBPy}$ and $d$-DBPy is supported by different intermolecular interactions and two regio-isomers favor entirely different molecular arrays not only in the solid phase but also at the solid-liquid interface. 


\section{Conclusion}

In summary, we have carried out a systematical investigation of 2D self-assembled monolayers for the regio-isomeric DPP derivatives ( $p$-DBPy and $d$-DBPy) formed at 1-phenyloctane /HOPG interface and 1-octanoic acid/HOPG interface using STM, respectively. Our aim is to explore how the slight difference in position of $\mathrm{N}$-atoms in pyridyl influences the molecular packing. It is interesting to find that the orientation of pyridyl unit relative to the DPP moiety has absolutely impact on the resulting self-assembled patterns. At the 1-phenyloctane/graphite surface, the conjugated cores of $p$-DBPy molecules adopt different conformations at different solution concentrations resulting from different intermolecular interactions. Although the conjugated moieties of $d$-DBPy display the same conformations, $d$-DBPy forms different nanopatterns at different solution concentrations, in which the side chains of $d$-DBPy exhibit different adsorbed fashions due to the molecular packing density. At the 1-octanoic acid/graphite surface, the $p$-DBPy and $d$-DBPy self-assembly into a dislocated segmented and wavy-like pattern, respectively, because of the polarity of the solvent. The identification of intermolecular interactions by STM can be utilized to explore the nature of the different morphology of the films. What is learn from STM results is therefore relevant for understanding the structure and local environment in the active layers of organic optoelectronic devices. 
Supplementary Information Available: Additional STM images. This material is available free of charge via the Internet at http://pubs.acs.org.

\section{AUTHOR INFORMATION}

\section{Corresponding Author}

*E-mail: msxrmiao@scut.edu.cn, fabien.silly@cea.fr

\section{Notes}

The authors declare no competing financial interest.

\section{ACKNOWLEDGMENT}

Financial supports from the National Natural Science Foundation of China (51373055and 21573077) and the Fundamental Research Funds for the Central Universities (SCUT) are gratefully acknowledged. X. Miao acknowledges receipt of the China Scholarship Council (CSC, 201706155092). This work is supported by a public grant overseen by the French National Research Agency (ANR) as part of the "Investissements d'Avenir" program (Labex NanoSaclay, reference: ANR-10-LABX-0035).

\section{REFERENCES}

(1) Li, W.; Hendriks, K. H.; Wienk, M. M.; Janssen, R. A. J., Diketopyrrolopyrrole Polymers for Organic Solar Cells. Accounts Chem. Res. 2016, 49, 78-85.

(2) Yao, J.; Yu, C.; Liu, Z.; Luo, H.; Yang, Y.; Zhang, G.; Zhang, D., Significant Improvement of Semiconducting Performance of the Diketopyrrolopyrrole-Quaterthiophene Conjugated Polymer through Side-Chain Engineering via Hydrogen-Bonding. J. Am. Chem. Soc. 2016, 138, 173-185.

(3) Qiao, Y.; Guo, Y.; Yu, C.; Zhang, F.; Xu, W.; Liu, Y.; Zhu, D., Diketopyrrolopyrrole-Containing Quinoidal Small Molecules for High-Performance, Air-Stable, and Solution-Processable n-Channel Organic Field-Effect Transistors. J. Am. Chem. Soc. 2012, 134, 4084-4087.

(4) Lee, G.-Y.; Han, A. R.; Kim, T.; Lee, H. R.; Oh, J. H.; Park, T., Requirements for Forming Efficient 3-D Charge Transport Pathway in Diketopyrrolopyrrole-Based Copolymers: Film Morphology vs Molecular Packing. ACS Appl. Mater. Interfaces 2016, 8, 12307-12315.

(5) Shin, W.; Yasuda, T.; Watanabe, G.; Yang, Y. S.; Adachi, C., Self-Organizing Mesomorphic 
Diketopyrrolopyrrole Derivatives for Efficient Solution-Processed Organic Solar Cells. Chem. Mater. 2013, $25,2549-2556$.

(6) Yue, J.; Sun, S.; Liang, J.; Zhong, W.; Lan, L.; Ying, L.; Huang, F.; Yang, W.; Cao, Y., Effects of Pyridyl Group Orientations on the Optoelectronic Properties of Regio-Isomeric Diketopyrrolopyrrole Based

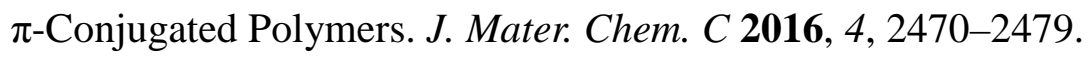

(7) Aytun, T.; Barreda, L.; Ruiz-Carretero, A.; Lehrman, J. A.; Stupp, S. I., Improving Solar Cell Efficiency through Hydrogen Bonding: A Method for Tuning Active Layer Morphology. Chem. Mater. 2015, 27, 12011209.

(8) Gevaerts, V. S.; Herzig, E. M.; Kirkus, M.; Hendriks, K. H.; Wienk, M. M.; Perlich, J.; Muller-Buschbaurn, P.; Janssen, R. A. J., Influence of the Position of the Side Chain on Crystallization and Solar Cell Performance of DPP-Based Small Molecules. Chem. Mater. 2014, 26, 916-926.

(9) Naik, M. A.; Venkatramaiah, N.; Kanimozhi, C.; Patil, S., Influence of Side-Chain on Structural Order and Photophysical Properties in Thiophene Based Diketopyrrolopyrroles: A Systematic Study. J. Phys. Chem. C 2012, 116, 26128-26137.

(10) Fu, C.; Belanger-Gariepy, F.; Perepichka, D. F., Supramolecular Ordering of Difuryldiketopyrrolopyrrole: the Effect of Alkyl Chains and Inter-Ring Twisting. CrystEngComm 2016, 18, $4285-4289$.

(11) Fu, C.; Lin, H.-p.; Macleod, J. M.; Krayev, A.; Rosei, F.; Perepichka, D. F., Unravelling the Self-Assembly of Hydrogen Bonded NDI Semiconductors in 2D and 3D. Chem. Mater. 2016, 28, 951-961.

(12) Yan, H.-J.; Sändig, N.; Wang, H.; Wang, D.; Zerbetto, F.; Zhan, X.; Wan, L.-J., Conformation Diversity of a Fused-Ring Pyrazine Derivative on Au(111) and Highly Ordered Pyrolytic Graphite. Chem. Asian J. 2015, 10, 1311-1317.

(13) Aytun, T.; Santos, P. J.; Bruns, C. J.; Huang, D.; Koltonow, A. R.; Olvera de la Cruz, M.; Stupp, S. I., Self-Assembling Tripodal Small-Molecule Donors for Bulk Heterojunction Solar Cells. J. Phys. Chem. C 2016, 120, 3602-3611.

(14) Kotwica, K.; Bujak, P.; Wamil, D.; Pieczonka, A.; Wiosna-Salyga, G.; Gunka, P. A.; Jaroch, T.; Nowakowski, R.; Luszczynska, B.; Witkowska, E.; Glowacki, I.; Ulanski, J.; Zagorska, M.; Pron, A., Structural, Spectroscopic, Electrochemical, and Electroluminescent Properties of Tetraalkoxydinaphthophenazines: New Solution-Processable Nonlinear Azaacenes. J. Phys. Chem. C 2015, $119,10700-10708$.

(15) Zhu, J.; Dong, Z.; Lei, S.; Cao, L.; Yang, B.; Li, W.; Zhang, Y.; Liu, J.; Shen, J., Design of Aromatic 
Helical Polymers for STM Visualization: Imaging of Single and Double Helices with a Pattern of $\pi-\pi$ Stacking. Angew. Chem. Int. Ed. 2015, 54, 3097-3101.

(16) Gutzler, R.; Sirtl, T.; Dienstmaier, J. r. F.; Mahata, K.; Heckl, W. M.; Schmittel, M.; Lackinger, M., Reversible Phase Transitions in Self-Assembled Monolayers at the Liquid-Solid Interface: Temperature-Controlled Opening and Closing of Nanopores. J. Am. Chem. Soc. 2010, 132, 5084-5090.

(17) Silly, F.. J. Phys. Chem. C 2013, 117, 20244-20249

(18) J. Hieulle, F. Silly, Localized Intermolecular Electronic Coupling in Two-Dimensional Self-Assembled 3,4,9,10-Perylenetetracarboxylic Diimide Nanoarchitectures, J. Mater. Chem. C 2013, 1, 4536-4539.

(19) Miao, X. R.; Xu, L.; Li, Z. M.; Deng, W. L., Solvent-Induced Structural Transitions of a 1,3,5-Tris(10-ethoxycarbonyldecyloxy)benzene Assembly Revealed by Scanning Tunneling Microscopy. $J$. Phys. Chem. C 2011, 115, 3358-3367.

(20) Peyrot, D.; Silly, F., Temperature-Dependent Structure of Two-Dimensional Hybrid NaCl-PTCDI Nanoarchitectures on Au(111). J. Phys. Chem. C 2017, 121, 20986-20993.

(21) Hua, Y.; He, J.; Zhang, C.; Qin, C.; Han, L.; Zhao, J.; Chen, T.; Wong, W.-Y.; Wong, W.-K.; Zhu, X., Effects of Various $\pi$-Conjugated Spacers in Thiadiazole[3,4-c]pyridine-cored Panchromatic Organic Dyes for Dye-Sensitized Solar Cells. J. Mater. Chem. A 2015, 3, 3103-3112.

(22) Donley, C. L.; Zaumseil, J.; Andreasen, J. W.; Nielsen, M. M.; Sirringhaus, H.; Friend, R. H.; Kim, J.-S., Effects of Packing Structure on the Optoelectronic and Charge Transport Properties in Poly(9,9-di-n-octylfluorene-alt-benzothiadiazole). J. Am. Chem. Soc. 2005, 127, 12890-12899.

(23) Sakakibara, K.; Chithra, P.; Das, B.; Mori, T.; Akada, M.; Labuta, J.; Tsuruoka, T.; Maji, S.; Furumi, S.; Shrestha, L. K.; Hill, J. P.; Acharya, S.; Ariga, K.; Ajayaghosh, A., Aligned 1-D Nanorods of a $\pi$-Gelator Exhibit Molecular Orientation and Excitation Energy Transport Different from Entangled Fiber Networks. $J$. Am. Chem. Soc. 2014, 136, 8548-8551.

(24) Zhao, Y. S.; Fu, H.; Peng, A.; Ma, Y.; Liao, Q.; Yao, J., Construction and Optoelectronic Properties of Organic One-Dimensional Nanostructures. Accounts Chem. Res. 2010, 43, 409-418.

(25) Welch, G. C.; Bakus, R. C.; Teat, S. J.; Bazan, G. C., Impact of Regiochemistry and Isoelectronic Bridgehead Substitution on the Molecular Shape and Bulk Organization of Narrow Bandgap Chromophores. J. Am. Chem. Soc. 2013, 135, 2298-2305.

(26) Coughlin, J. E.; Henson, Z. B.; Welch, G. C.; Bazan, G. C., Design and Synthesis of Molecular Donors for Solution-Processed High-Efficiency Organic Solar Cells. Accounts Chem. Res. 2014, 47, 257-70. 
(27) de Oteyza, D. G.; Gorman, P.; Chen, Y.-C.; Wickenburg, S.; Riss, A.; Mowbray, D. J.; Etkin, G.; Pedramrazi, Z.; Tsai, H.-Z.; Rubio, A.; Crommie, M. F.; Fischer, F. R., Direct Imaging of Covalent Bond Structure in Single-Molecule Chemical Reactions. Science 2013, 340, 1434-1437.

(28) Breuer, T.; Salzmann, I.; Götzen, J.; Oehzelt, M.; Morherr, A.; Koch, N.; Witte, G., Interrelation between Substrate Roughness and Thin-Film Structure of Functionalized Acenes on Graphite. Cryst Growth Des. 2011, 11, 4996-5001.

(29) Liu, G.; Liu, J.; Sun, H.; Zheng, X.; Liu, Y.; Li, X.; Qi, H.; Bai, X.; Jackson, K. A.; Tao, X., In Situ Imaging of On-Surface, Solvent-Free Molecular Single-Crystal Growth. J. Am. Chem. Soc. 2015, 137 , 4972-4975.

(30) Hu, J.; Wang, P.; Lin, Y.; Zhang, J.; Smith, M.; Pellechia, P. J.; Yang, S.; Song, B.; Wang, Q., Self-Assembly of Pyridinium-Functionalized Anthracenes: Molecular-Skeleton-Directed Formation of Microsheets and Microtubes. Chem. Eur. J. 2014, 20, 7603-7607.

(31) Li, Y.; Lee, D. H.; Lee, J.; Nguyen, T. L.; Hwang, S.; Park, M. J.; Choi, D. H.; Woo, H. Y., Two Regioisomeric $\pi$-Conjugated Small Molecules: Synthesis, Photophysical, Packing, and Optoelectronic Properties. Adv. Funct. Mater. 2017, 27, 1701942.

(32) Fan, B.; Ying, L.; Zhu, P.; Pan, F.; Liu, F.; Chen, J.; Huang, F.; Cao, Y., All-Polymer Solar Cells Based on a Conjugated Polymer Containing Siloxane-Functionalized Side Chains with Efficiency over 10\%. Adv. Mater. 2017, 29, 1703906.

(33) Silly, F., Concentration-dependent Two-Dimensional Halogen-Bonded Self-Assembly of 1,3,5-Tris(4-iodophenyl)benzene Molecules at the Solid-Liquid Interface. J. Phys. Chem. C 2017, 121, 10413-10418.

(34) Cheng, L.; Li, Y.; Zhang, C.-Y.; Gong, Z.-L.; Fang, Q.; Zhong, Y.-W.; Tu, B.; Zeng, Q.; Wang, a. C., Temperature-Triggered Chiral Self-Assembly of Achiral Molecules at the Liquid-Solid Interface. ACS Appl. Mater. Interfaces 2016, 8, 32004-32010.

(35) Cai, Z.-F.; Chen, T.; Gu, J.-Y.; Wang, D.; Wan, L.-J., Ionic Interaction-Induced Assemblies of Bimolecular "Chessboard" Structures. Chem. Commun. 2017, 53, 9129-9132.

(36) Xu, L.; Miao, X. R.; Zha, B.; Miao, K.; Deng, W. L., Dipole-Controlled Self-Assembly of 2,7-Bis(n-alkoxy)-9-fluorenone: Odd-Even and Chain-Length Effects. J. Phys. Chem. C 2013, 117, 1270712714.

(37) Wang, X. J.; Miao, X. R.; Ying, L.; Deng, W. L.; Cao, Y., Effect of Pyridyl Orientation on the Molecular Conformation and Self-Assembled Morphology of Regioisomeric Diketopyrrolopyrrole Derivatives. J. Phys. 
Chem. C 2017, 121, 19305-19313.

(38) Stepanenko, V.; Kandanelli, R.; Uemura, S.; Wurthner, F.; Fernandez, G., Concentration-Dependent Rhombitrihexagonal Tiling Patterns at the Liquid/Solid Interface. Chem. Sci. 2015, 6, 5853-5858.

(39) Hirsch, B. E.; McDonald, K. P.; Flood, A. H.; Tait, S. L., Living on the Edge: Tuning Supramolecular Interactions to Design Two-Dimensional Organic Crystals Near the Boundary of Two Stable Structural Phases. J. Chem. Phys. 2015, 142, 101914.

(40) Miyake, Y.; Nagata, T.; Tanaka, H.; Yamazaki, M.; Ohta, M.; Kokawa, R.; Ogawa, T., Entropy-Controlled 2D Supramolecular Structures of N,N'-Bis(n-alkyl)naphthalenediimides on a HOPG Surface. ACS Nano 2012, 6, 3867-3887.

(41) Miao, X. R,; Xu, L.; Cui, L. H.; Deng, W. L., Steric Matching and the Concentration Induced Self-Assembled Structural Variety of 2,7-Bis(n-alkoxy)-9-fluorenone at the Aliphatic Solvent/Graphite Interface. Phys. Chem. Chem. Phys. 2014, 16, 12544-12553.

(42) Liu, B.; Ran, Y.-F.; Li, Z.; Liu, S.-X.; Jia, C.; Decurtins, S.; Wandlowski, T., A Scanning Probe Microscopy Study of Annulated Redox-Active Molecules at a Liquid/Solid Interface: The Overruling of the Alkyl Chain Paradigm. Chem. Eur. J. 2010, 16, 5008-5012.

(43) Sun, X.; Lafolet, F.; Lemercier, G.; Maurel, F.; Lacroix, J.-C., Molecular Isomerization and Multiscale Phase Transitions of a Ditopic Ligand on a Surface. J. Phys. Chem. C 2017, 121, 20925-20930.

(44) Suzuki, M.; Guo, Z.; Tahara, K.; Kotyk, J. F. K.; Nguyen, H.; Gotoda, J.; Iritani, K.; Rubin, Y.; Tobe, Y., Self-Assembled Dehydro[24]annulene Monolayers at the Liquid/Solid Interface: Toward On-Surface Synthesis of Tubular $\pi$-Conjugated Nanowires. Langmuir 2016, 32, 5532-5541.

(45) Yang, Y.; Miao, X. R.; Liu, G.; Xu, L.; Wu, T. T.; Deng, W. L., Self-Assembly of Dendronized Non-Planar Conjugated Molecules on a HOPG Surface. Appl. Surf. Sci. 2012, 263, 73-78.

(46) Vonau, F.; Suhr, D.; Aubel, D.; Bouteiller, L.; Reiter, G.; Simon, L., Evolution of Multilevel Order in Supramolecular Assemblies. Phys. Rev. Lett. 2005, 94, 066103.

(47) Kim, S.; An, T. K.; Chen, J.; Kang, I.; Kang, S. H.; Chung, D. S.; Park, C. E.; Kim, Y.; Kwon, S., HAggregation Strategy in the Design of Molecular Semiconductors for Highly Reliable Organic Thin Film Transistors. Adv. Funct. Mater. 2011, 21, 1616-1623.

(48) Yagai, S.; Goto, Y.; Lin, X.; Karatsu, T.; Kitamura, A.; Kuzuhara D.; Yamada, H.; Kikkawa Y.; Saeki, A.; Seki S., Self-Organization of Hydrogen-Bonding Naphthalene Chromophores into J-type Nanorings and H-type Nanorods: Impact of Regioisomerism. Angew. Chem. 2012, 124, 6747 -6751. 